\title{
TC4 Titanium Alloy Microstructure and Properties Influenced by High Frequency Scan of Electron Beam
}

\author{
Xu Haiying ${ }^{1}, \quad$ Zhang Wei $^{2}, \quad$ Fan Kai $^{1}, \quad$ Fu Pengfei ${ }^{1}$ \\ ${ }^{1}$ Science and Technology on Power Beam Processes Laboratory, Beijing Aeronautical Manufacturing Technology Research Institute, Beijing \\ 100024, China; ${ }^{2}$ Beihang University, Beijing 100191, China
}

\begin{abstract}
In order to improve the HV hardness and microstructure on the surface of TC4 titanium alloy, the high frequency scan of electron beam (EB) was introduced to treat TC4 titanium alloy. For excellent parameters, the EB energy, focus current and scan times, which will influence the HV hardness and microstructures, were studied. After high frequency scan of electron beam treatment, the HV hardness, modified layer depth and microstructures of TC4 titanium alloy were analyzed. Results show that the HV hardness on the TC4 surface treated by the high frequency scan of electron beam can be increased by almost 40 MPa compared with that of the original material. With improved energy of EB, the depth layer influenced is increased. The focus current adjusted in a narrow range can acquire comparatively better HV hardness on the surface. When the scan times are increased, the HV hardness decreases, and the grains grow up.
\end{abstract}

Key words: TC4 titanium alloy; electron beam; high frequency scan

The titanium alloy surface modification technology includes ion implantation ${ }^{[1,2]}$, plasma spraying ${ }^{[3,4]}$, laser beam $^{[5]}$ and EB (electron beam) surface modification techniques ${ }^{[6]}$. For the restriction of energy of ion implantation, surface modification layer is shallow. The binding force of the coat by plasma spraying is low, which usually is only tens of $\mathrm{MPa}^{[7]}$. Comparing with ion implantation and plasma spraying technology, laser surface modification technology can significantly improve the surface hardness, wearable property and corrosion resistance. Thus, laser surface modification technology has been widely used. However, the energy conversion efficiency of the laser beam interaction with material is low, which is generally $5 \% \sim 10 \%{ }^{[8,9]}$. Moreover, it needs perfect protection during the titanium alloy material surface modification. Comparing with the laser surface modification technology, the energy conversion efficiency of EB interaction with the material can reach above $90 \%{ }^{[10-12]}$. Because of operation in a vacuum environment, there is almost no surface pollution. Besides, for the good controllability, the EB surface modification can easily realize the automation process.

According to the output beam type, the EB surface treatment technology can be classified into high current pulsed EB ${ }^{[13-15]}$ and continuous $\mathrm{EB}^{[16]}$.

The research about high current pulsed EB surface treatment technology mainly cared on the surface of steel, magnesium alloy and other materials modified ${ }^{[17]}$. In the past years, only a little research on titanium alloy treated by high current pulsed EB had been reported ${ }^{[18]}$. The special equipment will be required for high current pulsed EB surface treatment technology.

Comparatively, the continuous EB surface modification technology does not need special equipment. A traditional EB welding machine with high frequency deflection system can realize the EB material surface modification.

When the magnetic field changes at high frequency, the deflection angle of EB going through vertically will change

Received date: June 14, 2016

Foundation item: National Natural Science Foundation of China (2013E62519)

Corresponding author: Zhang Wei, Ph. D., Lecturer, School of Mechanical Engineering and Automation, Beihang University, Beijing 100191, P. R. China, Tel: 0086-10-82338416, E-mail: zhangweibh@buaa.edu.cn 
in the same frequency. According to this characteristic, the EB scan technology with high frequency is developed.

The EB scan technology with high frequency has been used in multi beam welding, EB treatment, etc.

In PTR Company at Germany, the EB scan with high frequency has been used to increase hardness on the surface of shafts, in order to improve its property of attrition.

Based on high frequency deflection scan of EB, surface modification technology for titanium alloy will be studied. By these studies, a new technology will be obtained, which will provide a well quality surface modification technology for titanium alloy in the future.

In the present study, the high frequency scan of EB has been employed to dispose TC4 titanium alloy. EB energy, focus current and scan times are crucial parameters for the high frequency scan of EB. With these parameters changed, TC4 titanium alloy surface hardness, modified layer depth and microstructures have been analyzed. At the same time, the mechanism of hardness layer on TC4 titanium alloy surface has be discussed.

\section{Experiment}

\subsection{Materials and parameters of EB machine}

TC4 (Ti-6Al-4V) is $\alpha+\beta$ type titanium alloy. 5.5wt $\% \sim 6.8$ wt $\%$ of the $\alpha$ stabilizing element Al, $3.5 \mathrm{wt} \% \sim 4.5 \mathrm{wt} \%$ of $\beta$ stabilizing elements $\mathrm{V}, \mathrm{Fe} \leq 0.3 \mathrm{wt} \%, \mathrm{C} \leq 0.1 \mathrm{wt} \%, \mathrm{~N} \leq 0.05$ $\mathrm{wt} \%, \mathrm{H} \leq 0.015 \mathrm{wt} \%, \mathrm{O} \leq 0.2 \mathrm{wt} \%$ and remnant Ti are $\mathrm{TC} 4$ nominal chemical composition. The specification of TC4 experiment sample is $30 \mathrm{~mm} \times 30 \mathrm{~mm} \times 5 \mathrm{~mm}$. The EB scan scope is $20 \mathrm{~mm} \times 20 \mathrm{~mm}$.

The power of EB welding machine is $60 \mathrm{~kW}$. The highest operation voltage is $150 \mathrm{kV}$. Work distance is $400 \mathrm{~mm}$. Another parameter will be changed according to the experimentation need.

\subsection{Scheme of EB scan}

As well known, the deflection of EB will take place when EB goes through a vertical magnetic field. The frequency of EB scan can be changed from several $\mathrm{Hz}$ to hundreds $\mathrm{kHz}$, which is named high frequency. In the high frequency status, EB energy can be controlled accurately. Generally, deflection magnetic field is consisted of two parts. One is $X$-direction magnetic field, the other is $Y$-direction magnetic field. These magnetic fields are produced by symmetrical coils along axis. These coils are named $X$-direction coil and $Y$-direction coil. The change of current in coil will change magnetic field, thus the deflection angle will be adjusted synchronously.

In the present study, $10 \mathrm{~mA}$ beam current and $0.1 \mathrm{~mm}$ diameter beam spot had been used largely. In order to achieve full scan scope at $20 \mathrm{~mm} \times 20 \mathrm{~mm}$, the scan mode of line by line has been employed. This scan mode is shown in Fig.1a. It can be seen from Fig.1a that two hundred $X$-direction scans can cover the sample along $Y$-direction.
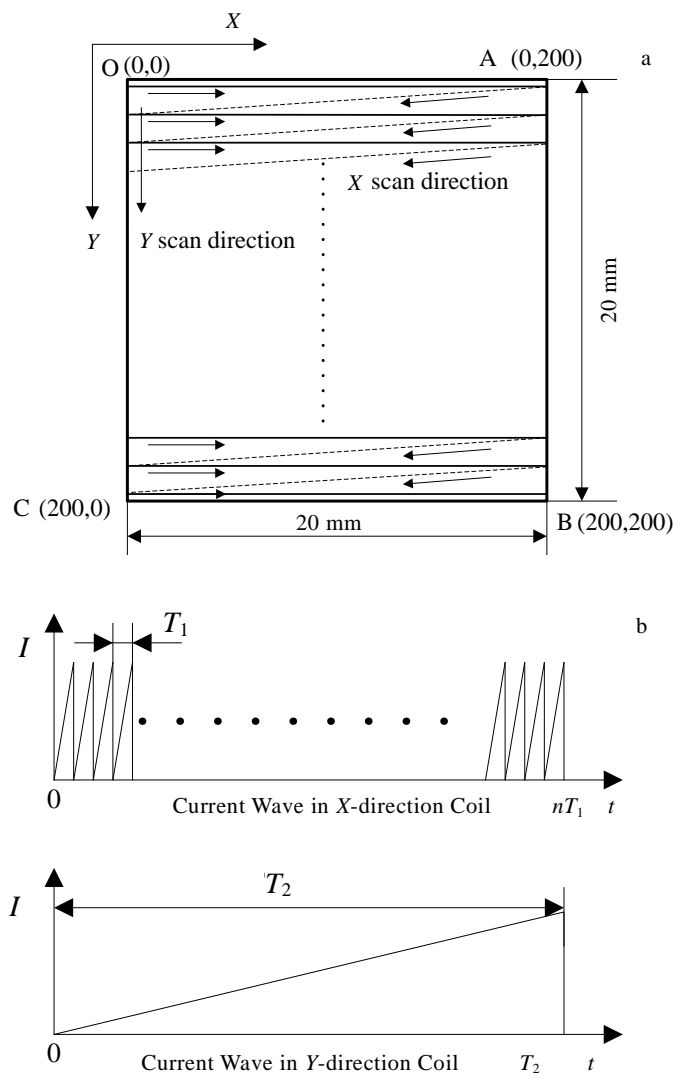

Fig. 1 Scan mode (a) and scan wave of $T_{1}$ and $T_{2}$ (b)

The current waves in $X$-direction coil and $Y$-direction coil are shown in Fig.1b. For example, if the scan frequency of $Y$-direction is up to $500 \mathrm{~Hz}$, the scan frequency of $X$-direction will be $100 \mathrm{kHz}$.

In order to acquire super technology of high frequency scan of EB, the HV hardness and microstructures affected by high frequency EB scan were researched.

\section{Results and Discussion}

\subsection{HV hardness analysis}

The surface HV hardness of samples treated by several parameters of high frequency scan of EB had been tested. The DHV-1000 micro hardness test apparatus was adopted to detect the surface micro-hardness. The $1000 \mathrm{~g}$ test load and 15 s load residence time were chosen as test condition. On the test surface of the TC4 titanium, six test points with 1 $\mathrm{mm}$ interval were detected. Besides, six test points were done along a line. The start test point was in the center of the TC4 samples.

When the EB energy, focus current or scan times change, the HV hardness of the surface will be influenced by these parameters.

\subsubsection{HV hardness influenced by EB energy}

Besides the changed EB energy, other parameters were kept unchanged. The constant parameters are listed in Table 1. 
Table 1 Constant parameters with EB energy changed

\begin{tabular}{ccccc}
\hline Voltage/kV & $\begin{array}{c}\text { Work } \\
\text { distance/mm }\end{array}$ & $\begin{array}{c}\text { Focus } \\
\text { current/mA }\end{array}$ & $\begin{array}{c}\text { Frequency/ } \\
\mathrm{kHz}\end{array}$ & $\begin{array}{c}\text { Scan } \\
\text { times }\end{array}$ \\
\hline 150 & 400 & 2485 & 96.48 & 10 \\
\hline
\end{tabular}

When EB energy increases from $4 \mathrm{~mA}$ to $18 \mathrm{~mA}$, the $\mathrm{HV}$ hardness influenced by EB energy is shown in Fig.2. As Fig. 2 shown, the HV hardness is improved, except for $4 \mathrm{~mA}$ beam current.

Comparing that of with that of original material of TC4 titanium alloy, the HV hardness on the surface treated by 4 $\mathrm{mA}$ beam current is lower. When the EB energy exceeds 10 $\mathrm{mA}$, the hardness on the TC4 surface will be improved. The average $\mathrm{HV}$ hardness is $3980 \mathrm{MPa}$ when the $13 \mathrm{~mA}$ beam current was introduced to treat the surface.

\subsubsection{HV hardness influenced by focus current}

When the focus current was changed, other parameters remain constant, which are shown in Table 2.

Fig. 3 shows the HV hardness influenced by different focus currents. In Fig.3, it is found that the HV hardness can be accordant at $4824 \mathrm{~mA}$ EB focus current. The HV hardness undulate range is larger at another focus current introduced. Considering the microstructures change, this phenomenon will be discussed as follows.

\subsubsection{HV hardness influenced by EB scan times}

Besides the EB scan times changed, $10 \mathrm{~mA}$ focus current and other parameters shown in Table 2 were kept unchanged.

The status about HV hardness influenced by different scan times is shown in Fig. 4.

It can be seen from Fig. 4 that the HV hardness on TC4 surface treated by high frequency scan of EB will be decreased, with the scan times increasing. When the scan times are less than 10, the HV hardness on TC4 surface will be enhanced.

\subsection{Microstructure analysis}

Not only HV hardness on the surface is influenced by the high frequency scan of EB, but also the microstructure will be changed. For every sample, microstructure on the surface and the microstructure at section were detected. The microstructure and alterant layer influenced by different parameters of high frequency scan will be analyzed as follows.

\subsubsection{Microstructure influenced by EB energy}

When the EB energy was changed, other parameters were kept invariables (see Table 1). The 4, 10, 13, 16, $18 \mathrm{~mA}$ were introduced to treat the surface of TC4 titanium alloy. It is found that the surface of TC4 titanium alloy is hardly influenced by EB less than $4 \mathrm{~mA}$.

The typical microstructures on the surface of TC4 titanium alloy are shown in Fig. 5. As shown in Fig. 5, TC4 titanium alloy was melted at $16 \mathrm{~mA}$ electron beam.

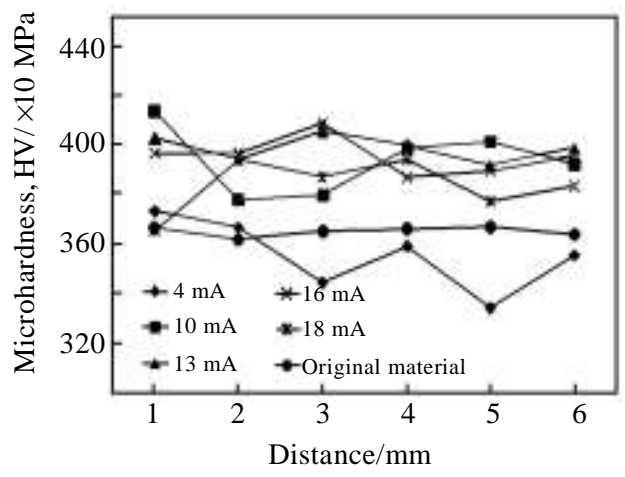

Fig.2 Influence of EB energy on HV microhardness

Table 2 Constant parameters with focus current changed

\begin{tabular}{ccccc}
\hline $\begin{array}{c}\text { Voltage/ } \\
\mathrm{kV}\end{array}$ & $\begin{array}{c}\text { Work } \\
\text { distance } / \mathrm{mm}\end{array}$ & $\begin{array}{c}\mathrm{EB} \\
\text { energy/mA }\end{array}$ & $\begin{array}{c}\text { Frequency } \\
/ \mathrm{kHz}\end{array}$ & $\begin{array}{c}\text { Scan } \\
\text { times }\end{array}$ \\
\hline 150 & 400 & 10 & 96.48 & 10 \\
\hline
\end{tabular}

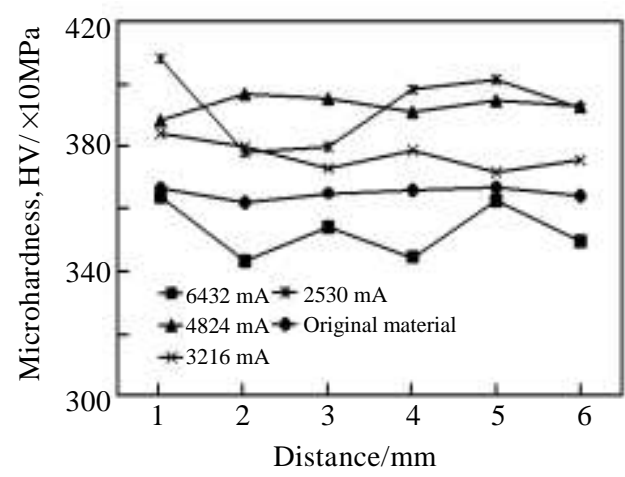

Fig.3 Influence of EB focus current on HV microhardness

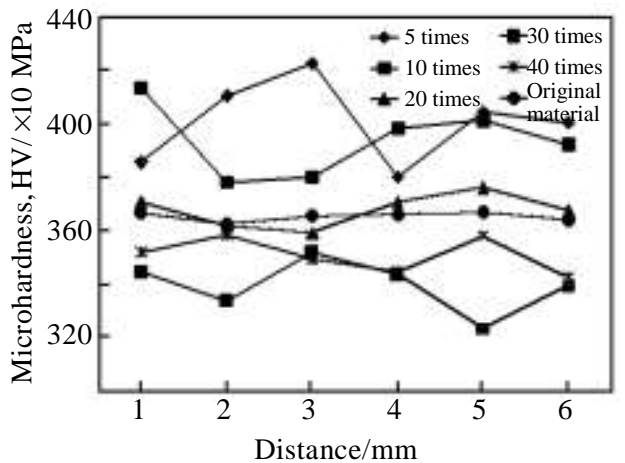

Fig.4 Influence of EB scan times on HV microhardness

The $\beta$ phase grains shown in Fig. 5 are clear. Also, the long needle shape $\alpha^{\prime}$ phase can be seen in the initial $\beta$ phase grains. This phenomena indicates that these grains grow up during the high frequency scan of EB operation. 


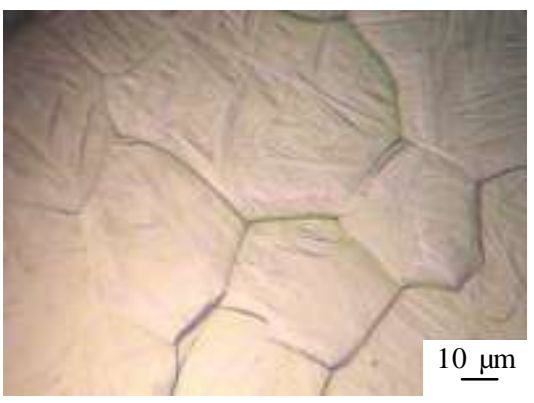

Fig.5 Microstructure on surface with 16 mA EB energy

The typical microstructures at cross-section influenced by EB energy are shown in Fig.6. At $10 \mathrm{~mA} \mathrm{~EB}$ current, the depth of the influence layer doesn't exceed $160 \mu \mathrm{m}$. Nevertheless, when EB energy is increased to $16 \mathrm{~mA}$ for the high frequency scan, the depth of the influence layer exceeds $300 \mu \mathrm{m}$. Fine grains are distributed equably in the influence layer. From the top to bottom on the cross-section of TC4 titanium alloy, there are a fine grain zone and based material in turn. In the fine grain zone, the short club-shaped microstructure, punctate microstructures and little sheet microstructures are distributed desultorily.

In the based material, there are equiaxed grains of $\alpha$ phase and $\beta$ phase distributed in the grain boundary. The HAZ can't be seen in these metallography images. Because high frequency EB can heat samples quickly as well as cool to metal fast for large base material, the fine grains can be brought.

Comparing Fig.2, Fig. 5 and Fig. 6, it can draw a conclusion that the HV hardness is increased because of fine gains on the surface of TC4 titanium alloy treated by high frequency scan of EB.

\subsubsection{Microstructure influenced by focus current}

When the parameters, which are shown in Table 2, were kept invariable, these microstructures for focus current adjusted had been detected. Fig.7 shows microstructure of section influenced by different focus current.

The different focus currents mean focus location are different. Surface focus can be obtained at $2485 \mathrm{~mA}$ focus current. When focus current is increased over $2485 \mathrm{~mA}$, the electron beam diameter will be increased. At the same time, focus location changes from surface focus to top focus. When the focus current is set over $2485 \mathrm{~mA}$, the electron beam energy is emanative hardly, which weakens penetrating property.

By a series of experimentations, it can be found that the surface HV hardness will be changed by the modulating of focus current. At $6432 \mathrm{~mA}$ focus current, there are coarse grains at the section, which will bring on lower HV hardness. At $4824 \mathrm{~mA}$ focus current, coarse grains of $\beta$

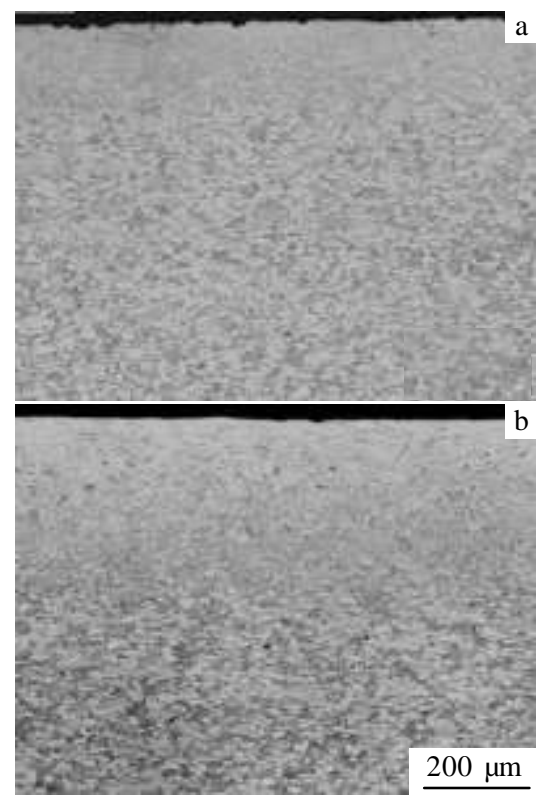

Fig. 6 Cross section microstructures with $10 \mathrm{~mA}$ (a) and $16 \mathrm{~mA}$ (b) EB energy

phase appears at surface layer, which is up to several $\mu \mathrm{m}$. Because of the HV hardness increasing, it is possible that a lot of titanium martensite microstructures appear in the influence layer, which need more research in the future. At other focus current, which is less than $4824 \mathrm{~mA}$ and larger than $2485 \mathrm{~mA}$, the sheet $\alpha$ phase disappear. At the same time, there are many club-shaped microstructures, which make the HV hardness on the surface to be higher than original material.

\subsubsection{Microstructure influenced by EB scan times}

As EB scan times are different, the heat input is different, which means that grown degree of grains is different. Thus, the influence of EB scan times on microstructure is studied. Fig. 8 presents the microstructure on the surface of TC4 samples which had been treated by different EB scan times.

At 5 times EB scan, microstructures are hardly changed. The surface metal will melt little at 10 times EB scan. When the times of EB scan is increased up to 20 times, the surface metal is melted heavily. Coarse grains can be seen in Fig. 8b and Fig.8c, and a series of needle shape microstructure can be seen in the initial $\beta$ phase grains. As Fig. 8 shown, with the times of EB scan increasing, grains on the surface will grow up. By 20 times EB scan, the dimension of grain is over $10 \mu \mathrm{m}$. There are several grains in the scope, which is shown in Fig. 8b. When the EB scan times increase continually, the grains grow up quickly. There is only a whole grain shown in Fig.8c. 


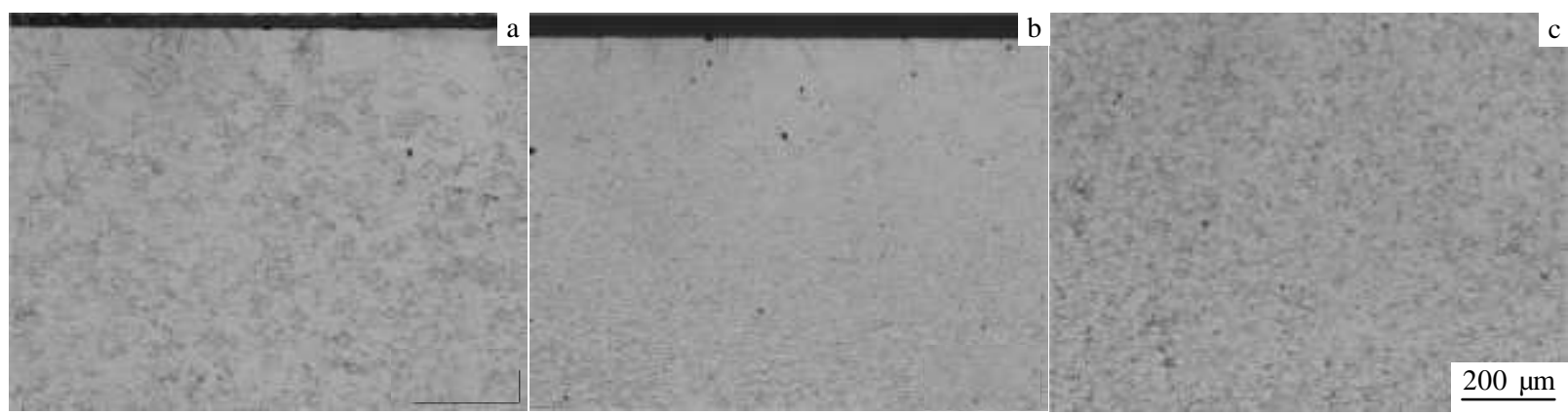

Fig.7 Microstructures of the cross section with different focus current: (a) $6432 \mathrm{~mA}$, (b) $4824 \mathrm{~mA}$, and (c) $3216 \mathrm{~mA}$

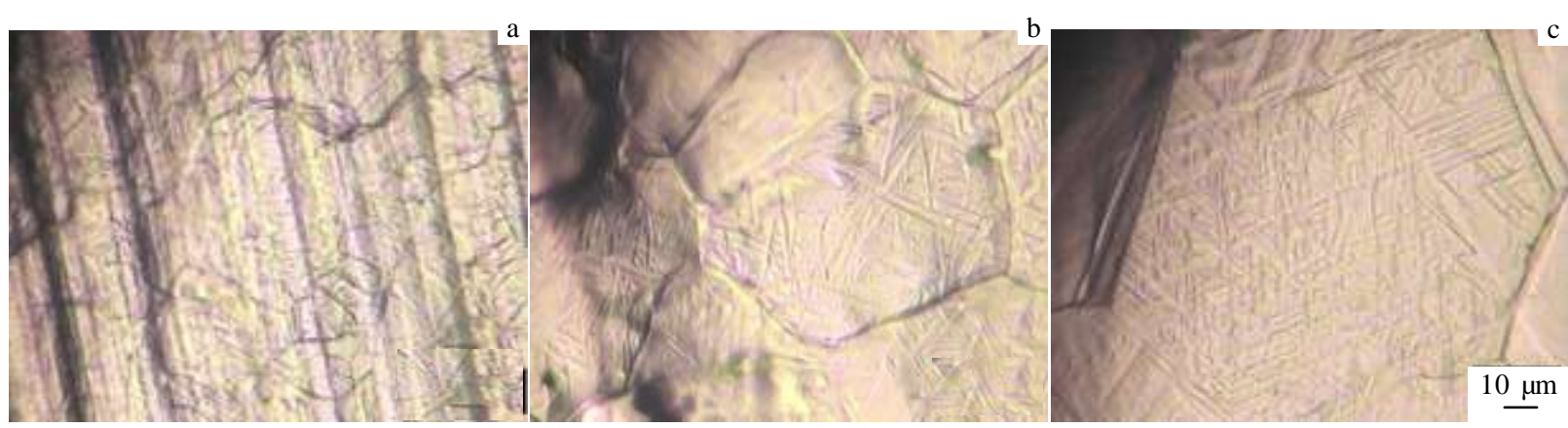

Fig. 8 Microstructures on the surface with different EB scan times: (a) 10, (b) 20, and (c) 30
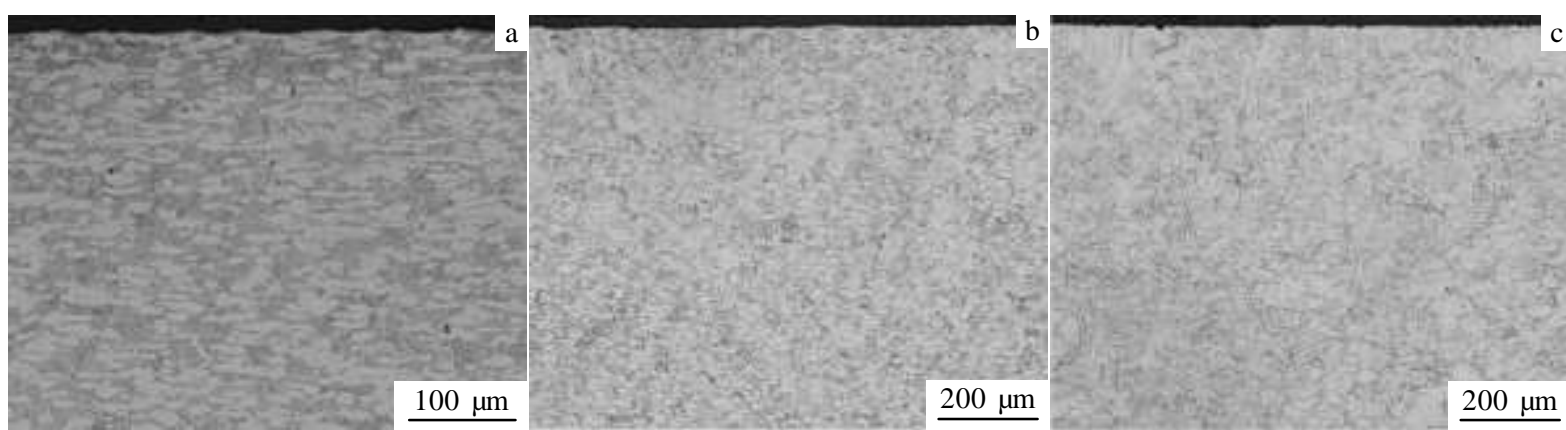

Fig.9 Microstructures in the depth direction with different EB scan times: (a) 5, (b) 20, and (c) 30

EB scan times increasing means enhanced heat input. It will change microstructure of TC4 titanium alloy in the depth direction. Fig. 9 shows the change of microstructure in the depth direction with EB scan times adjusted.

At five times EB scan, the influence layer is only several $\mu \mathrm{m}$. The microstructure at cross-section treated by 10 times EB scan can be seen in Fig. 6a. In this metallography microstructure, $150 \mu \mathrm{m}$ thick influence layer can be seen. At twenty times EB scan, the depth of the influence layer exceeds a $500 \mu \mathrm{m}$. When EB scan times is increased continually, the depth of the influence layer will exceed 1 $\mathrm{mm}$. The microstructures will grow up severely by thirty times EB scan adopted. It can be seen from Fig.9c that coarse columniation grains point to TC4 alloy surface. The initial $\beta$ phase grains are impenetrated by long needle shape $\alpha^{\prime}$ phase and lath shape $\alpha$ phase. Because of coarse grains, the HV hardness is decreased. The mechanism of $\mathrm{HV}$ hardness decreasing with the EB scan times increased need to be studied deeply.

\section{Conclusions}

1) When the operation voltage, working distance and scan frequency are unchangeable, energy of $\mathrm{EB}$, focus current and scan times are key parameters to affect the $\mathrm{HV}$ hardness and microstructures of titanium alloy.

2) At other parameters kept unchanged, energy of EB improved will increase influence layer depth along with coarse grains appearing. 
3) When other parameters are invariable, focus current adjusted in a narrow range can acquire comparatively better HV hardness on the surface.

4) At other parameters kept changeless, the scan times increased continually induce the $\mathrm{HV}$ hardness to be decreased and the grains to be grown up.

\section{References}

1 Wang Junshi, Yan Yonghua, Chen Guirong. Chinese Journal of Rare Metals[J], 2006(5): 583 (in Chinese)

2 Hu Fanjun, Pan Qingmao. China Surface Engineering[J], 2003, 16(2): 44 (in Chinese)

3 Chen Limei, Li Qiang. Heat Treatment Technology and Equipment[J], 2006, 26(1): 1 (in Chinese)

4 Wang Shaopeng, Li Zhengxian, Du Jihong. Surface Technology [J], 2013, 41(5): 95

5 Wang Dongsheng, Tian Zongjun, Shen Lida et al. laser \& Optoelectronics Progress[J], 2008, 45(6): 24 (in Chinese)

6 Dipllng H Schultz. Electron Beam Welding[M]. Cambridge England: Woodhead Publishing Ltd in association with The Welding Institute, 1993

7 Chen Fei, Zhou Hai, Luo Wei. Hot Working Technology[J], 2008, 37(13): 96 (in Chinese)
8 Hao shengzhi, Dong Chuang. China Patent, CN101582367A [P]. 2009 (in Chinese)

$9 \mathrm{Xu}$ Haiying, Zuo Congjin et al. China Patent, 201310346979.3[P]. 2013 (in Chinese)

10 Yan Xiaofeng. Aeronautical Manufacturing Technology[J], 2005(9): 90 (in Chinese)

11 Chen Yuanfang, Xian Yang, Jin Tieyu et al. Modern Manufacturing Engineering[J], 2009(8): 153 (in Chinese)

12 Zhang Wenfeng, Zhu Di. New Technology Material Surface Treatment $[\mathrm{J}]$, 2003(8): 41

13 Hao Shengzhi, Wu Pingsheng, Zhang Xiangdong et al. Heat Treatment of Metals[J], 2008, 33(1): 77 (in Chinese)

14 Hao Shengzhi, Gao Bo, Wu Aimin et al. Nuclear Instruments and Methods in Physics Research[J], 2005, 240(B): 648

15 Ahmad M, Akhter J I, Shaikh M A. Journal of Alloys and Compounds[J], 2006, 422: 99

16 Song Yimei, Li Shaolin, Zhong Qinghua. Guangxi Machinery [J], 2003(1): 17 (in Chinese)

17 Wang Xuetao, Guan Qingfeng, Qiu Donghua et al. Acta Physica Sinica[J], 2010, 59(10): 7252 (in Chinese)

18 Zhang Xiangdong, Hao Shengzhi, Grosdidier Thierry et al. Heat Treatment of Metals[J], 2010, 35(12): 40 (in Chinese)

\title{
电子束高频扫描对 TC4 钛合金组织性能影响的研究
}

\author{
许海鹰 ${ }^{1}$, 张 伟 ${ }^{2}$, 范 恺 ${ }^{1}$, 付鹏飞 ${ }^{1}$ \\ (1. 北京航空制造工程研究所 高能束流加工技术重点实验室, 北京 100024) \\ (2. 北京航空航天大学, 北京 100191)
}

\begin{abstract}
摘 要: 为了提高 TC4 钛合金表面硬度和改善微观组织, 采用高频电子束扫描对 TC4 钛合金表面进行处理。为了获得良好的电子束高 频扫描工艺参数, 分别研究了电子束能量、聚焦电流、扫描频率等工艺参数调整时, TC4 钛合金表面硬度和微观组织变化。对经过不 同工艺处理的 TC4 钛合金, 分别检测了表面硬度、表面组织、硬化层深度、硬化层内部组织。结果表明: 与未经处理的 TC4 母材相比, 经过电子束高频扫描处理的 TC4 钛合金表面硬度增加了 $40 \mathrm{MPa}$ 以上; 随着电子束能量增加，影响深度增大; 聚焦电流在小范围内调 整, 可获得较高的表面硬度; 处理区域的表面硬度逐渐减小, 晶粒增大; 其它工艺参数不变时, 随着扫描次数增大, 表面硬度逐渐降 低, 影响层的晶粒逐渐粗化。
\end{abstract}

关键词: TC4 钛合金; 高频扫描; 电子束

作者简介: 许海鹰, 男, 1973 年生, 博士, 高级工程师, 北京航空制造工程研究所高能束流加工技术重点实验室, 北京 100024 , 电 话: 010-85701494, E-mail: xhyxhy@126.com 